\title{
UTILIZAÇÃO DA SERRAGEM DE Eucalyptus spp. PARA A PRODUÇÃO DE TIJOLO MACIÇO CERÂMICO
}

\author{
Fábio Akira Mori ${ }^{1}$, Murilo Morgandi Covezzi ${ }^{2}$, Cláudia Lopes Selvati de Oliveira Mori ${ }^{2}$ \\ ${ }^{1}$ Eng. Florestal, Dr., Depto. de Ciências Florestais, UFLA, Lavras, MG, Brasil - morif@dcf.ufla.br \\ 2Eng. Florestal, UFLA, Lavras, MG, Brasil - covezzi@ hotmail.com; selvaticl@uol.com.br
}

Recebido para publicação: 18/05/2009 - Aceito para publicação: 30/05/2011

\begin{abstract}
Resumo
Objetivou-se neste trabalho verificar a viabilidade do processo de incorporação de serragem de Eucalyptus spp. para a confecção de produtos cerâmicos; avaliar em ensaios preliminares de laboratório o comportamento da argila e dos tratamentos constituídos com traços de mistura argila/serragem; avaliar a composição química da serragem e proceder a uma análise mineralógica da argila pelo teste de difração de raios X. Utilizaram-se 10 tratamentos com a mistura argila/serragem: 1:0 (testemunha), 2:1, 3:1, 4:1, 5:1, 6:1, 7:1, 8:1, 9:1 e 10:1. As características físicas e mecânicas das amostras foram determinadas. Verificou-se que existe a viabilidade técnica de incorporação em diferentes misturas de argila/serragem de Eucalyptus para produção de produtos cerâmicos. Em relação à resistência mecânica dos tijolos produzidos, uma boa incorporação foi de oito partes de argila e uma de serragem. Nas demais propriedades físicas, uma incorporação de no mínimo seis partes de argila e uma parte de serragem. Na análise mineralógica por difração de raios X, a argila caracterizou-se como caulinítica. Através dos testes realizados, observou-se que o peso dos corpos de prova com essa incorporação foi, em média, 12,7\% menor do que o dos constituídos somente de argila.

Palavras-chave: Serragem de Eucalyptus; tijolo cerâmico.
\end{abstract}

\begin{abstract}
Eucalyptus sawdust utilization to massive ceramic brick production. This research has as its main aims: to evaluate the Eucalyptus sawdust incorporation feasibility for ceramics production, analyzing in laboratory initial analysis the behavior of clay/sawdust mixture compared to a control treatment; to evaluate the chemical composition of the sawdust; to carry on a mineralogical analysis of the clay by XRay diffraction test. In order to do that, ten treatments for bricks production had been improved, based on the following clay/sawdust rates: 1:0, 2:1, 3:1, 4:1, 5:1, 6:1, 7:1, 8:1, 9:1 and 10:1. The physical and mechanical properties of the samples were subsequently determined. It was verified that there are technical viability of incorporation in different mixtures of clay/sawdust of Eucalyptus for production of ceramic products. In relation to mechanical resistance of the produced bricks a good incorporation was of eight parts of clay and one of sawdust. In relation to the other physical properties there is an incorporation of at least six parts of clay and one of sawdust. In the mineralogical clay analysis by XRay diffraction it was characterized as caulinitic. Accordingly to the accomplished tests, it was observed that the average weight of the proof bodies with this incorporation was $12,7 \%$ smaller than the ones constituted only of clay.
\end{abstract}

Keywords: Eucalyptus sawdust; ceramic brick.

\section{INTRODUÇÃO}

Ao se avaliar um novo composto para a produção de materiais cerâmicos, utiliza-se a prerrogativa de se ensaiar esse composto em laboratório, uma vez que testes industriais são bastante onerosos. Esses ensaios são denominados ensaios preliminares de argilas desconhecidas ou ensaios de caracterização de argilas, visando prever usos industriais e, em especial, usos cerâmicos. Os ensaios têm por objetivos prever, adaptar ou sugerir novos usos para argilas que serão utilizadas apenas para uma finalidade industrial, correlacionar as propriedades cerâmicas, composição mineralógica e propriedades intrínsecas aos usos industriais específicos e também originar estudos científicos fundamentais em argilas brasileiras. 
Assim, caracterizar uma argila, especialmente vislumbrando o seu uso tecnológico, é conhecer a variabilidade de suas propriedades, o que não é um problema simples e necessita não somente do emprego de técnicas comuns (como a de mensurar suas propriedades físico-mecânicas), mas também de técnicas sofisticadas (as de análise de características mineralógicas). Principalmente para a indústria de cerâmica vermelha, esses ensaios possuem a finalidade de determinar experimentalmente as características, composição e propriedades tecnológicas do futuro produto que se deseja produzir.

Alguns materiais (resíduos) estão sendo incorporados à argila experimentalmente na produção de produtos cerâmicos, entre eles o pó de ardósia e a serragem de madeira. Esse processo, além de evitar o desperdício, proporciona uma utilização mais nobre e diminui o impacto ambiental causado pela destinação final inadequada desses materiais. A utilização de materiais ligno-celulósicos, como a serragem, ocasiona a redução no peso do material, importante variável na projeção de materiais para a construção civil, como é o caso dos tijolos maciços cerâmicos. Alguns estudos preliminares mostram redução de peso em torno de 20 a $30 \%$ do tijolo maciço cerâmico.

A fabricação de tijolos destinados à construção é a mais antiga arte da humanidade. Além dos gregos, egípcios e assírios, que utilizavam tijolos queimados nas suas construções, também os romanos e os árabes os difundiram, empregando-os como adornos e em belas combinações geométricas (MÜLLER, 1990). Segundo Verçosa (1979), os materiais cerâmicos mais comuns são os materiais de barro comum, utilizados na construção civil, tanto na forma de tijolos como de telhas.

Entretanto, existe uma nova gama de produtos derivados dos produtos cerâmicos visando o aproveitamento de resíduos, que encontramos em abundância, devido ao consumismo humano e a industrialização de produtos das mais diversas procedências. Alguns exemplos desses produtos já estão sendo implantados e outros em fase de testes, como o tijolo de plástico e madeira, de cimento e madeira, de argila com borra de petróleo, de argila com resíduos do processo de produção da pasta de celulose e tijolos de argila com serragem de madeira (COVEZZI, 1999).

Estudos de Covezzi (1999) demonstram a viabilidade de incorporar 10\% de serragem de Erisma uncinatum WARM. (cedrinho) para produção de tijolo maciço cerâmico. O peso do tijolo confeccionado com essa serragem foi inferior em 16,4\% ao manufaturado somente com argila pura. Com base na normatização da Associação Brasileira de Normas Técnicas (ABNT) para produtos cerâmicos acabados, podem-se confeccionar blocos cerâmicos, ou seja, tijolos de até 8 furos, com essa serragem.

A premissa de se incorporar resíduos vem da necessidade de se aproveitar matérias-primas industrializadas e comercializadas nos mais diversos ramos que, sem esse aproveitamento, estão causando problemas de ordem econômica e ambiental. Entre os setores, o que mais produz resíduos é o florestal, pois, desde a extração da árvore até o seu produto final industrializado, gera em torno de $70 \%$ de resíduos, que muitas vezes não são aproveitados ou são simplesmente queimados. Portanto, procurou-se desenvolver este trabalho objetivando a utilização do resíduo de madeira de Eucalyptus na fabricação de tijolos maciços e, por meio dessa modalidade de incorporação, diminuir os custos de produção, bem como diminuir o impacto ambiental causado pela não utilização racional desses resíduos.

Este trabalho teve como finalidade estudar a viabilidade técnica de incorporação da serragem de Eucalyptus spp. na fabricação de produtos cerâmicos, através da avaliação em laboratório de diferentes traços da mistura (argila/serragem), e analisar as características dos componentes empregados nos testes (argila e serragem).

\section{MATERIAL E MÉTODOS}

\section{Coleta do material}

Para este estudo, utilizou-se a serragem de toras de clones de Eucalyptus spp. proveniente do processamento mecânico em serra circular múltipla, material este oriundo da serraria de propriedade da Companhia Mineira de Metais (CVV-AGRO), localizada no município de Paracatu (MG). Coletaram-se doze sacos contendo cerca de $25 \mathrm{~kg}$ de serragem, com restos de casca e pedaços maiores de madeira. $\mathrm{O}$ material foi transportado para o Laboratório de Tecnologia da Madeira do Departamento de Ciências Florestais da Universidade Federal de Lavras (MG), onde se procedeu ao peneiramento manual da serragem em peneira com abertura de $1,0 \mathrm{~mm}^{2}$. Após o preparo, a serragem foi transportada para o Laboratório de Cerâmica do Centro de Formação "Paulo de Tarso" (Serviço Nacional de Aprendizagem Industrial, SENAI), Belo Horizonte (MG). 
A argila utilizada foi coletada na cerâmica Morgan, no município de Rio Acima (MG). Foram coletados cinco sacos de $50 \mathrm{~kg}$ de material em seu estado bruto (entorroada, com raízes e ainda úmida), preparado da seguinte forma:

- espalhe para redução da umidade - o espalhe consistiu em espalhar a argila em camadas finas sobre uma superfície plana e bem protegida da chuva por 24 horas, para que houvesse a evaporação e consequente redução da umidade do material;

- moagem da argila - a argila foi moída por um "moinho martelo", para ser destorroada e ser diminuído o tamanho das partículas, preparando-a para a etapa seguinte;

- peneiramento - o peneiramento foi manual, com peneiras de abertura de $2,0 \mathrm{~mm} / 9 \mathrm{mesh}$ e $0,850 \mathrm{~mm} / 20 \mathrm{mesh}$, através das quais foram separadas as partículas maiores e eliminadas algumas impurezas, como pedaços de raízes.

- Desse material, retirou-se uma amostra para as respectivas análises por difração de raios X, realizadas no Laboratório de Solos do Departamento de Ciência do Solo da Universidade Federal de Lavras (MG).

\section{Preparação das diferentes concentrações de serragem e argila}

Com a argila e a serragem preparadas, procedeu-se à elaboração dos diferentes traços de mistura de argila e serragem. Para cada mistura (argila + serragem), pesaram-se $10 \mathrm{~kg}$ de material, resguardadas as proporções em volume de cada componente. Como se apresenta na tabela 1, para o preparo utilizou-se uma caixa de madeira de $10 \mathrm{~cm}^{3}$ para medir as proporções.

Tabela 1. Tratamentos com os traços de mistura em partes $(\mathrm{P})$, proporção e porcentagem de componentes.

Table 1. Treatments with traces of the moisture parts (P), proportional and percentage of components.

\begin{tabular}{lccccc}
\hline Tratamento & P. Argila & P. Serragem & Proporção & \% Argila & \% Serragem \\
\hline Testemunha & 01 & 00 & $1: 0$ & 100,0 & 00,00 \\
$\mathrm{~A}_{2}$ & 02 & 01 & $2: 1$ & 66,67 & 33,33 \\
$\mathrm{~A}_{3}$ & 03 & 01 & $3: 1$ & 75,00 & 25,00 \\
$\mathrm{~A}_{4}$ & 04 & 01 & $4: 1$ & 80,00 & 20,00 \\
$\mathrm{~A}_{5}$ & 05 & 01 & $5: 1$ & 83,33 & 16,67 \\
$\mathrm{~A}_{6}$ & 06 & 01 & $6: 1$ & 85,71 & 14,29 \\
$\mathrm{~A}_{7}$ & 07 & 01 & $7: 1$ & 87,50 & 12,50 \\
$\mathrm{~A}_{8}$ & 08 & 01 & $8: 1$ & 88,89 & 11,11 \\
$\mathrm{~A}_{9}$ & 09 & 01 & $9: 1$ & 90,00 & 10,00 \\
$\mathrm{~A}_{10}$ & 10 & 01 & $10: 1$ & 90,91 & 09,09 \\
\hline
\end{tabular}

Após a pesagem de cada componente dos tratamentos, incorporou-se um ao outro, com uma préhomogeneização manual.

\section{Umedecimento e homogeneização das amostras}

As amostras constituídas foram homogeneizadas manualmente, adicionando-se água na proporção de 20 a $25 \%$ em relação ao peso total da amostra, perfazendo um total entre 2000 e $2500 \mathrm{~mL}$ para cada amostra, até elas adquirirem uma boa plasticidade. Em seguida, as amostras foram colocadas em sacos plásticos e deixadas em descanso por 24 horas, objetivando a distribuição homogênea da umidade em toda a mistura-amostra.

\section{Extrusão/confecção de corpos de prova}

Após o período de descanso, procedeu-se à extrusão da mistura, usando-se um equipamento denominado maromba ou extrusora (Figura 1), que é constituído de um misturador, uma câmara de vácuo e uma extrusora. Fez-se a passagem do material pela maromba até que se conseguisse um estado plástico adequado. Por meio de um cortador manual, procedeu-se à confecção de corpos de prova com dimensões nominais de $11,0 \mathrm{~cm}$ de comprimento, $1,9 \mathrm{~cm}$ de espessura e 2,9 $\mathrm{cm}$ de largura no momento da extrusão, perfazendo um total de quarenta corpos de prova por tratamento, segundo norma NBR 7170/83 (ABNT, 1983). 

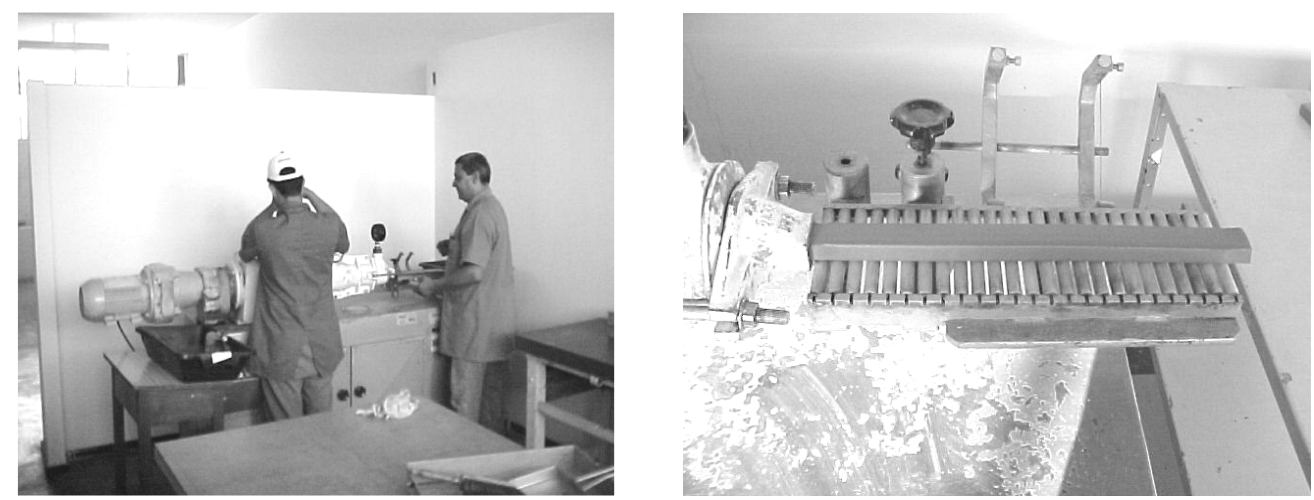

Figura 1. Extrusão dos corpos de prova.

Figure 1. Extrusion the body test.

\section{Numeração e marcação de corpos de prova}

Dos 40 (quarenta) corpos de prova confeccionados, escolheram-se 24 ao acaso, segundo NBR 7170/83 (ABNT, 1983), os quais foram divididos em três grupos de oito corpos de prova (CP), sendo que dois grupos de amostra receberam numeração, em uma das faces, de 1 a 8 (indicando o $\mathrm{n}^{\circ}$ do $\mathrm{CP}$ e a identificação do tratamento T, A2, A3, A4, A5, A6, A7, A8, A9, A10), o número zero, indicando que o grupo passaria pela secagem à temperatura de $110^{\circ} \mathrm{C}$ (teste de tensão de ruptura à flexão a $110^{\circ} \mathrm{C}$ ) e o número 1 , indicando a passagem pelos processos de secagem à temperatura de $110^{\circ} \mathrm{C}$ e queima à temperatura de $950{ }^{\circ} \mathrm{C}$ (testes de umidade de extrusão, perda ao fogo e tensão de ruptura à flexão a $950^{\circ} \mathrm{C}$ ). Também se procedeu à confecção (utilizando-se um paquímetro digital) de duas marcas paralelas no meio de todos os corpos de prova, com $5,50 \mathrm{~cm}$ de espaçamento entre eles, pela qual se fez o teste de retração (Figura 2). O terceiro grupo recebeu somente a marcação do tratamento e o $\mathrm{n}^{\circ}$ do corpo de prova. Esse grupo, entretanto, passou pelos processos de secagem, queima e cozimento e foi utilizado para os testes de absorção d'água, porosidade aparente e massa específica aparente.

Após essa numeração e marcação, os corpos de prova foram deixados por 72 horas em repouso, para secagem ao ar livre, para haver a evaporação do excesso da umidade, procedimento que inibe o aparecimento de rachaduras e trincas no momento da secagem a $110^{\circ} \mathrm{C}$. Além disso, os corpos de prova foram individualmente apoiados sobre a espessura, para evitar empenamentos.
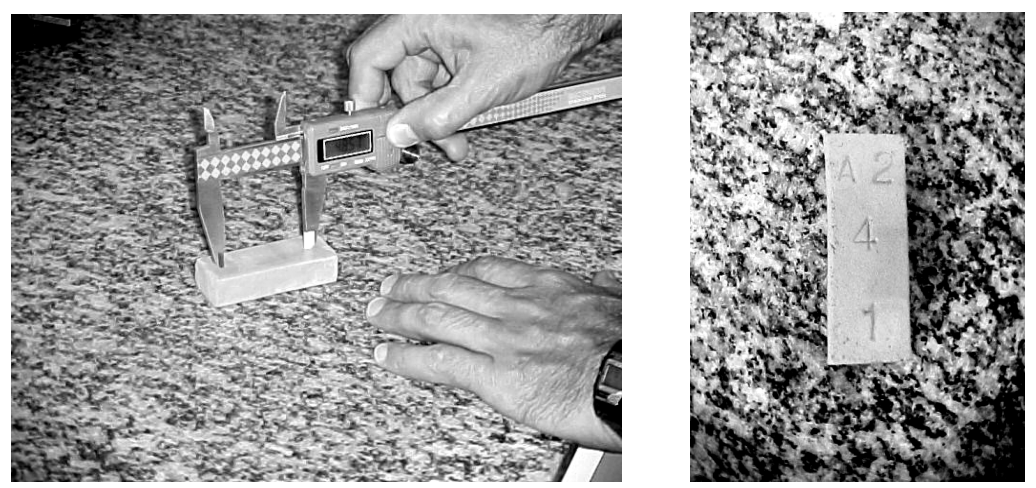

Figura 2. Marcação e numeração dos corpos de prova.

Figure 2. Marking and numeration the test bodies.

\section{Secagem e queima de corpos de prova}

Após todos esses procedimentos, todos os corpos de prova numerados com números 0 e 1 foram colocados em uma estufa e secados por 24 horas a uma temperatura de $110^{\circ} \mathrm{C}$. Após essa etapa, apenas os corpos de prova com o número 1 foram colocados em uma mufla e queimados por 24 horas à 
temperatura de $950^{\circ} \mathrm{C}$. Depois dessas etapas de secagem e queima, os corpos de prova estavam prontos para os ensaios em laboratório.

\section{Ensaios físicos e mecânicos nos corpos de prova}

Os ensaios físicos e mecânicos seguiram a metodologia de Cocchi (1990).

\section{Ensaios físicos dos corpos de prova}

Determinação da umidade de extrusão (U)

Após extrusão, pesou-se cada corpo de prova, individualmente, em balança eletrônica com precisão de $0,01 \mathrm{~g}(\mathrm{Mu})$. Em seguida, eles foram submetidos a secagem por 72 horas à temperatura ambiente. Após essa etapa, procedeu-se a secagem por 24 horas à temperatura de $110{ }^{\circ} \mathrm{C} \mathrm{em}$ estufa. Decorrido esse tempo, os corpos de prova foram colocados em dessecador e pesados novamente (Ms). A umidade de extrusão foi calculada pela seguinte expressão:

$$
\mathrm{U}(\%)=\frac{\mathrm{Mu}-\mathrm{Ms}}{\mathrm{Ms}} \times 100
$$

em que: $\mathrm{U}=$ porcentagem de umidade;

$\mathrm{Mu}=$ massa úmida $(\mathrm{g})$;

Ms = massa seca $(\mathrm{g})$.

Determinação da perda ao fogo (PF)

Secaram-se os corpos prova em estufa a $110{ }^{\circ} \mathrm{C}$ por 24 horas, sendo deixados para esfriar em dessecador. Cada corpo de prova foi pesado em balança eletrônica com precisão de $0,01 \mathrm{~g}$ (Ms). A seguir, realizou-se a queima dos corpos de prova à temperatura de $950{ }^{\circ} \mathrm{C}$ em uma mufla, sendo deixados para esfriar em dessecador e serem novamente pesados (Mq). A perda ao fogo foi então calculada pela seguinte expressão:

$$
P F(\%)=\frac{M s-M q}{M s} \times 100
$$

em que: $\mathrm{PF}=$ perda ao fogo $(\%)$;

$\mathrm{Ms}=$ massa seca $(\mathrm{g})$

$\mathrm{Mq}=$ massa queimada $(\mathrm{g})$.

Determinação da retração de secagem (RS), retração de queima (RQ) e retração total (RT)

$\mathrm{O}$ material foi deixado esfriar em dessecador e mediu-se a retração das marcas com paquímetro (Rs). Calcularam-se as retrações por meio das seguintes expressões:

$$
\mathrm{Rs}(\%)=\frac{\mathrm{Ci}-\mathrm{Cs}}{\mathrm{Ci}} \times 100
$$

em que: Rs = retração após secagem $(\%)$;

$\mathrm{Ci}=$ comprimento inicial $(\mathrm{cm})$;

$\mathrm{Cf}=$ comprimento após secagem $(\mathrm{cm})$.

Em seguida, procedeu-se a queima por 24 horas, em mufla, à temperatura de $950{ }^{\circ} \mathrm{C}$, e a seguir o material foi deixado esfriar em dessecador. Procedeu-se novamente a medição das marcas, obtendo-se (Rq) pela seguinte expressão:

$$
\mathrm{Rq}(\%)=\frac{\mathrm{Cs}-\mathrm{Cq}}{\mathrm{Cs}} \times 100
$$

em que: $\mathrm{Rq}=$ retração após queima $(\%)$;

Cs = comprimento após secagem $(\mathrm{cm})$;

$\mathrm{Cq}=$ comprimento após queima $(\mathrm{cm})$.

A retração total foi calculada pela seguinte expressão:

$$
\operatorname{Rt}(\%)=\frac{\mathrm{Ci}-\mathrm{Cq}}{\mathrm{Ci}} \times 100
$$


em que: $\mathrm{Rt}=$ retração total $(\%)$;

$\mathrm{Cs}=$ comprimento inicial $(\mathrm{cm})$;

$\mathrm{Cq}=$ comprimento após queima $(\mathrm{cm})$.

Determinação da absorção d'água (Aa), porosidade aparente (Pa) e massa específica aparente (Mea)

Os corpos de prova do $3^{\circ}$ grupo, após passarem pelo processo de secagem e queima, foram pesados individualmente em balança eletrônica com precisão de $0,01 \mathrm{~g}$ (Ms). Imergiram-se os corpos de prova em água, recipientes de alumínio, os quais foram aquecidos em fogão a gás industrial e deixados ferver por duas horas, contadas após o início da fervura. Deixou-se o material esfriar até temperatura ambiente. Esses corpos de prova foram mantidos sempre imersos em água e foram pesados imersos em água, pelo método da balança hidrostática, através do qual obteve-se o peso imerso (Mi). Com um pano úmido, retirou-se o excesso de água da superfície de cada corpo de prova e então se procedeu à pesagem, obtendo-se a massa do corpo de prova saturado de água $(\mathrm{Mu})$, calculada por meio das expressões:

$$
\% A a=\frac{(M u-M s)}{M s} \times 100
$$

em que: \%Aa = porcentagem de Absorção de água;

$\mathrm{Mu}=$ massa úmida $(\mathrm{g})$;

Ms $=$ massa seca $(\mathrm{g})$.

$$
P a=\frac{M u-M s}{M u-M i} \times 100(\%)
$$

$$
\text { em que: } \begin{aligned}
\mathrm{Pa} & =\text { porosidade aparente }(\%) \\
\mathrm{Mu} & =\text { massa úmida }(\mathrm{g}) \\
\mathrm{Ms} & =\text { massa seca }(\mathrm{g}) \\
\mathrm{Mi} & =\text { massa imersa }(\mathrm{g})
\end{aligned}
$$

$$
M E A=\frac{M s}{M s-M i}
$$

em que: MEA = massa específica aparente $\left(\mathrm{g} / \mathrm{cm}^{3}\right)$;

Ms = massa seca $(\mathrm{g})$;

$\mathrm{Mi} \quad=$ massa imersa $(\mathrm{g})$.

\section{Ensaio mecânico dos corpos de prova}

Determinação da tensão de ruptura à flexão (TRF)

$\mathrm{O}$ ensaio de tensão de ruptura à flexão foi realizado com os dois grupos de corpos de prova, o que passou pelo processo de secagem a $110{ }^{\circ} \mathrm{C}$ e o que passou pela queima a $950{ }^{\circ} \mathrm{C}$. Observou-se o rompimento respectivo de cada um e anotou-se a carga máxima de ruptura.

O equipamento utilizado para a execução do ensaio foi uma máquina universal de ensaio EMIC DL30000, provida de um dispositivo que assegura a distribuição uniforme da carga sobre o corpo de prova. O corpo de prova fica apoiado sobre os cutelos, permitindo que a carga seja aplicada progressivamente até o rompimento (Figura 3).

Utilizou-se a metodologia discriminada a seguir: mediu-se a largura (b) e a espessura (a) dos corpos de prova após secagem a $110{ }^{\circ} \mathrm{C}$ e queima a $950{ }^{\circ} \mathrm{C}$, e depois anotou-se o valor da distância entre cutelos de apoio $(\mathrm{L}=7,5 \mathrm{~cm})$. Os corpos de prova foram apoiados um a um sobre os dois cutelos, na máquina de ensaio universal, e em seguida acertou-se a escala de leitura e a velocidade de aplicação da carga $(10 \mathrm{~N} / \mathrm{s})$ para corpo de prova seco/queimado. Então se deu o procedimento de ensaio até que o corpo de prova se rompesse. Após o rompimento, fez-se a leitura da carga de ruptura (kgf) e calculou-se a $\mathrm{TRF}$ em $\mathrm{kgf} / \mathrm{cm}^{2}$, pela expressão dada a seguir, para corpos de prova de seção quadrada ou retangular. Ao final, apresentaram-se os valores médios.

$$
T R F=\frac{3 \times P \times L}{2 \times a^{2} \times b}
$$

em que: TRF = tensão de ruptura à flexão $\left(\mathrm{kgf} / \mathrm{cm}^{2}\right)$ ou MPa;

$\mathrm{P} \quad=$ carga de ruptura $(\mathrm{kgf})$;

L = distância dos cutelos (vão livre) $(\mathrm{cm})$;

a $=$ espessura $(\mathrm{cm})$;

$\mathrm{b} \quad=$ largura $(\mathrm{cm})$. 

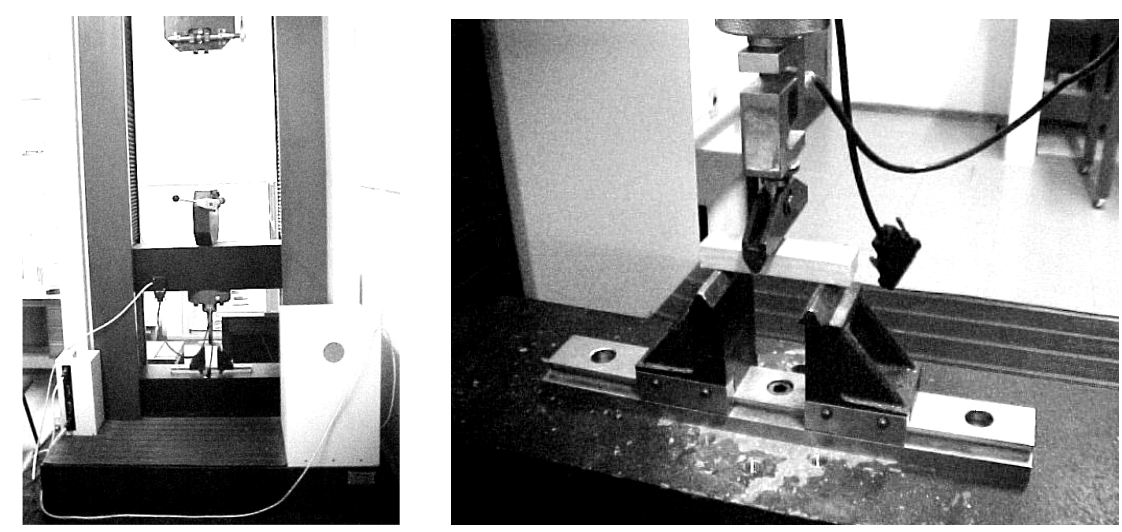

Figura 3. Máquina universal de ensaio - EMIC DL30000.

Figure 3. Universal machine of assay - EMIC DL30000.

\section{Delineamento estatístico}

Para a análise estatística, utilizou-se o delineamento experimental inteiramente casualizado com 8 repetições, conforme o seguinte modelo estatístico:

$$
\mathrm{Yi}=\mu+\mathrm{ti}+\mathrm{ei}
$$

em que: $Y_{i}=$ efeito do i-ésimo valor observado do tratamento i;

$\mu=$ constante inerente a todas as observações (média geral);

$t_{i}=$ efeito do i-ésimo tratamento, efeito fixo;

$\mathrm{e}_{\mathrm{i}}=$ erro experimental associado à observação $\mathrm{Y}_{\mathrm{i}}$.

Foi ainda realizado um teste de comparação de médias, utilizando-se o teste de Dunnett em nível de 5\% de probabilidade (BANZATTO; KRONKA, 1985).

\section{Ensaios em laboratório de determinação dos componentes da argila e da serragem de Eucalyptus Análise da argila por difração de raios $X$}

As análises com a argila foram efetuadas no Laboratório de Análise de Solo do Departamento de Ciências do Solo da UFLA, em um aparelho de raios X PHILLIPS PW 1830, através do qual foi efetuada a caracterização mineralógica do material por difratometria de Raios-X, na amostra desferrificada e ao natural, empregando-se tubo de cobalto no intervalo de irradiação de 5 a $50^{\circ} 2 \theta$.

\section{Análise química da serragem}

Procedeu-se à análise química para determinar os componentes secundários, minerais, polissacarídeos e lignina da serragem de Eucalyptus, utilizando-se as normas da Associação Brasileira de Celulose e Papel (ABCP): M4/68, M3/1969, M2/1971, M10/1971 e M11/1971. Essas análises foram executadas no Laboratório de Tecnologia da Madeira do Departamento de Ciências Florestais da UFLA.

\section{RESULTADOS E DISCUSSÃO}

A tabela 2 mostra os valores de referência para as características físicas e mecânicas avaliadas nos testes preliminares de argilas em laboratório com o intuito de prever a sua utilização na produção de materiais cerâmicos.

Os resultados médios para as características dos corpos de prova analisadas, bem como o teste de comparação múltipla, são apresentados na tabela 3.

\section{Umidade de extrusão}

$\mathrm{Na}$ tabela 3 pode-se observar que os valores da umidade de extrusão foram superiores ao recomendado pelo SENAI (1999), que sugere que esse valor deve estar entre 18 e $35 \%$. O valor médio apresentado para essa característica foi de $36,55 \%$, variando de 35,0 a $38,7 \%$. Essa característica depende do tamanho e do tipo de partícula mineral, ou seja, da composição química, morfologia e estrutura da partícula. O conhecimento da umidade de extrusão (U) é importante para que se tenha uma indicação da 
quantidade de água a ser incorporada no processo de fabricação do tijolo, prever que tipo de processo de secagem deve ser utilizado para retirar essa umidade, bem como evitar trincas e lascamentos das peças cerâmicas cruas. A argila deve ser moldada com uma quantidade de água que permita a sua conformação e não afete a sua plasticidade.

Tabela 2. Valores de referência padrões das características físicas e mecânicas e temperatura na qual o corpo de prova é submetido ao teste.

Table 2. Values of reference standard of the physical and mechanical characteristics and temperature in which the test body is submitted to the test.

\begin{tabular}{lcc}
\hline Ensaio & Temperatura $\left({ }^{\circ} \mathbf{C}\right)$ & Variação padrão (\%) \\
\hline Umidade de extrusão (\%) (U) & 110 & 18 a 35 \\
Perda ao fogo (\%) (PF) & 950 & $<10$ \\
Retração de secagem (\%) (RS) & 110 & $<6$ \\
Retração de queima (\%) (RQ) & 950 & $<6$ \\
Retração total (\%) (RT) & 950 & $<12$ \\
Porosidade aparente (\%) (Pa) & 950 & 17 a 35 \\
Massa específica aparente $\left(\mathrm{g} / \mathrm{cm}^{3}\right)(\mathrm{MEA})$ & 950 & $>1,7$ \\
Absorção d'água (\%) $(\mathrm{Aa})$ & 950 & 8 a 25 \\
Tensão de ruptura à flexão $\left(\mathrm{kgf} / \mathrm{cm}^{2}\right)(\mathrm{TRF} 110)$ & 110 & 15 \\
Tensão de ruptura à flexão $\left(\mathrm{kgf} / \mathrm{cm}^{2}\right)($ TRF950) & 950 & 20 \\
\hline
\end{tabular}

Fonte: SENAI (1999).

\section{Perda ao fogo}

A perda ao fogo (PF) é a característica que a argila possui de diminuir de volume pela perda da umidade de constituição, de matéria orgânica e de outros elementos constantes em sua constituição mineral, os quais se volatilizam com o aumento da temperatura de queima. Seu valor padrão é de no máximo $10 \%$ (SENAI, 1999). Essa característica apresentou valor médio de 10,19\%, variando, nos tratamentos, de 6,8 a $15,0 \%$. Observa-se na tabela 3 que todos os tratamentos diferiram da testemunha. Esse fato é normal, devido à incorporação de material orgânico à argila e que a serragem é material combustível.

Tabela 3. Valores médios para as características físicas e mecânicas dos corpos de prova analisados em laboratório para diversos tratamentos.

Table 3. Average values for the physical and mechanical characteristics of the analyzed bodies test in laboratory for diverse treatments.

\begin{tabular}{|c|c|c|c|c|c|c|c|c|c|c|}
\hline Tratamentos & $\begin{array}{c}\mathrm{U} \\
(\%)\end{array}$ & $\begin{array}{l}\text { PF } \\
(\%)\end{array}$ & $\begin{array}{l}\text { RS } \\
(\%)\end{array}$ & $\begin{array}{l}\text { RQ } \\
(\%)\end{array}$ & $\begin{array}{l}\text { RT } \\
(\%)\end{array}$ & $\begin{array}{l}\text { MEA } \\
\mathrm{g} / \mathrm{cm}^{3}\end{array}$ & $\begin{array}{c}\mathbf{P a} \\
(\%)\end{array}$ & $\begin{array}{l}\text { Aa } \\
(\%)\end{array}$ & $\begin{array}{l}\text { TRF110 } \\
\text { kgf/cm }\end{array}$ & $\begin{array}{l}\text { TRF950 } \\
\text { kgf/cm }\end{array}$ \\
\hline $\mathrm{T}$ & $36,5 \mathrm{a}$ & 6,8 a & $4,4 \mathrm{a}$ & $2,2 \mathrm{a}$ & $6,5 \mathrm{a}$ & $1,6 \mathrm{a}$ & $40,2 \mathrm{a}$ & $25,5 \mathrm{a}$ & $12,0 \mathrm{a}$ & $69,5 \mathrm{a}$ \\
\hline 10:01 & $35,0 \mathrm{~b}$ & $8,4 \mathrm{~b}$ & $2,8 \mathrm{~b}$ & $1,5 \mathrm{a}$ & $4,2 \mathrm{~b}$ & $1,6 \mathrm{a}$ & $39,6 \mathrm{a}$ & $25,6 \mathrm{a}$ & $11,3 \mathrm{a}$ & $61,0 \mathrm{a}$ \\
\hline 09:01 & $35,0 \mathrm{~b}$ & $9,0 \mathrm{~b}$ & $2,4 \mathrm{~b}$ & $3,1 \mathrm{a}$ & $5,4 \mathrm{a}$ & $1,5 \mathrm{~b}$ & $41,3 \mathrm{a}$ & $27,0 \mathrm{a}$ & $10,3 \mathrm{~b}$ & $87,5 \mathrm{a}$ \\
\hline 08:01 & $35,3 \mathrm{~b}$ & $9,0 \mathrm{~b}$ & $2,6 \mathrm{~b}$ & $1,7 \mathrm{a}$ & $4,3 \mathrm{~b}$ & $1,5 \mathrm{a}$ & $40,4 \mathrm{a}$ & $26,3 \mathrm{a}$ & $11,5 \mathrm{a}$ & $66,0 \mathrm{a}$ \\
\hline 07:01 & $37,4 \mathrm{~b}$ & $9,4 \mathrm{~b}$ & $3,1 \mathrm{~b}$ & $2,9 \mathrm{a}$ & 5,9 a & $1,5 \mathrm{~b}$ & $42,5 \mathrm{~b}$ & $28,7 \mathrm{~b}$ & $10,9 \mathrm{~b}$ & $77,2 \mathrm{a}$ \\
\hline 06:01 & $36,5 \mathrm{a}$ & $9,9 \mathrm{~b}$ & $2,2 \mathrm{~b}$ & $0,6 \mathrm{~b}$ & $2,8 \mathrm{~b}$ & $1,5 \mathrm{a}$ & $40,5 \mathrm{a}$ & $26,4 \mathrm{a}$ & $11,3 \mathrm{a}$ & $54,8 \mathrm{a}$ \\
\hline 05:01 & $37,5 \mathrm{~b}$ & $10,3 \mathrm{~b}$ & $2,5 \mathrm{~b}$ & $0,9 \mathrm{~b}$ & $3,4 \mathrm{~b}$ & $1,6 \mathrm{a}$ & $39,7 \mathrm{a}$ & $25,3 \mathrm{a}$ & $10,8 \mathrm{~b}$ & 58,8 a \\
\hline 04:01 & $37,3 \mathrm{~b}$ & $11,5 \mathrm{~b}$ & $2,3 \mathrm{~b}$ & $2,1 \mathrm{a}$ & $4,4 \mathrm{~b}$ & $1,5 \mathrm{~b}$ & $41,7 \mathrm{a}$ & $27,5 \mathrm{a}$ & $11,3 \mathrm{a}$ & 70,8 a \\
\hline 03:01 & $36,2 \mathrm{~b}$ & $12,6 \mathrm{~b}$ & $2,0 \mathrm{~b}$ & $2,2 \mathrm{a}$ & $4,2 \mathrm{~b}$ & $1,5 \mathrm{~b}$ & $43,1 \mathrm{~b}$ & $28,8 \mathrm{~b}$ & $11,6 \mathrm{a}$ & $63,7 \mathrm{a}$ \\
\hline 02:01 & $38,7 \mathrm{~b}$ & $15,0 \mathrm{~b}$ & $2,6 \mathrm{~b}$ & $4,0 \mathrm{~b}$ & $6,5 \mathrm{a}$ & $1,4 \mathrm{~b}$ & $49,1 \mathrm{~b}$ & $36,0 \mathrm{~b}$ & $11,5 \mathrm{a}$ & $62,5 \mathrm{a}$ \\
\hline Média & 36,55 & 10,19 & 2,68 & 2,12 & 4,75 & 1,52 & 41,81 & 27,70 & 11,24 & 67,17 \\
\hline C.V. $(\%)$ & 0,44 & 0,79 & 16,16 & 44,30 & 18,69 & 2,95 & 3,46 & 5,72 & 6,55 & 28,06 \\
\hline
\end{tabular}

Médias com letras idênticas nas colunas indicam a não existência de diferença significativa entre o tratamento testemunha e os demais, pelo teste de Dunnett em nível de 5\% de probabilidade. U: umidade de extrusão (\%); PF: perda ao fogo (\%); RS: retração de secagem (\%); RQ: retração de queima (\%); RT: retração total $(\%)$; MEA: massa específica aparente $\left(\mathrm{g} / \mathrm{cm}^{3}\right)$; Pa: porosidade aparente $(\%)$; Aa: absorção d'água $(\%)$; TRF110: tensão de ruptura à flexão $110^{\circ} \mathrm{C}\left(\mathrm{kgf} / \mathrm{cm}^{2}\right)$; TRF950: tensão de ruptura à flexão $950{ }^{\circ} \mathrm{C}\left(\mathrm{kgf} / \mathrm{cm}^{2}\right)$. 


\section{Retração de secagem}

Para a retração de secagem (RS), todos os tratamentos apresentaram valor médio de 2,68\%, variando de $2,0 \%$ a $4,4 \%$, valores, portanto, dentro do padrão de $6 \%$ (SENAI, 1999). Como a retração de secagem varia em função da plasticidade e da perda de umidade, não deve apresentar valor muito elevado, para não dificultar o processo de conformação do produto cerâmico. No caso específico da argila em estudo, ficou constatado no processo de extrusão dos corpos de prova que a plasticidade da mesma era mediana.

\section{Retração de queima}

$\mathrm{Na}$ retração de queima (RQ), o valor médio apresentado foi de 2,12\%, variando de 0,6 a 4,0\%, valores abaixo do limite de 6\% (SENAI, 1999). Apesar de os valores dos tratamentos estarem dentro do padrão, o seu comportamento foi diferente, devido ao fato de a retração de queima estar diretamente relacionada à perda de matéria orgânica e outros componentes da argila.

\section{Retração total}

A retração total (RT), que é a soma das duas retrações descritas anteriormente, apresentou valor médio de $4,75 \%$ e variou de 2,8 a $6,5 \%$, valores inferiores em relação ao limite de $12 \%$ (SENAI, 1999).

Esse comportamento das retrações, apresentando valores abaixo do padrão, pode ser explicado pela presença de quartzo na constituição da argila. O quartzo (sílica livre) causa redução da plasticidade e também leva a uma baixa retração linear. Além disso, sabendo-se o valor da retração, pode-se calcular o tamanho em que a peça deve ser moldada e cortada para que o produto atinja o tamanho adequado de comercialização após passar pelo processo de queima, em conformidade com as normas técnica da ABNT para produtos cerâmicos acabados.

\section{Massa específica aparente}

$\mathrm{Na}$ característica massa específica aparente (MEA) da parte sólida, todos os tratamentos apresentaram valores variando entre $1,4 \mathrm{~g} / \mathrm{cm}^{3}$ e $1,6 \mathrm{~g} / \mathrm{cm}^{3}$ e valor médio de $1,52 \mathrm{~g} / \mathrm{cm}^{3}$, valores inferiores ao valor padrão, que é de no mínimo $1,7 \mathrm{~g} / \mathrm{cm}^{3}$ (SENAI, 1999).

\section{Porosidade aparente}

A argila em estudo apresentou valores entre $49,1 \%$ e $39,6 \%$ e um valor médio de $41,81 \%$. Todos os tratamentos apresentaram valores de porosidade aparente (PA) acima da padronização, que é entre 17 e $35 \%$ (SENAI, 1999). Essa característica é a relação entre o volume de poros e o volume total. As argilas que possuem em sua composição minerais de granulometria grossa possuem menos poros e estes são maiores nas argilas de estruturas mais finas. O comportamento observado nos tratamentos foi o esperado, já que, em percentuais elevados de incorporação de serragem, os tratamentos apresentaram valores maiores que a testemunha. Entretanto, alguns tratamentos apresentaram valores menores que a testemunha. Esse fato foi também observado em experimento similar ao presente estudo, para a espécie Erisma uncinatum (cedrinho ou quarubarana) (COVEZZI, 1999).

\section{Absorção d'água}

A absorção d'água apresentou valores variando entre 36,0 e 25,3\% e um valor médio de $27,7 \%$, sendo que o valor padrão para absorção d'água (Aa) em produtos cerâmicos é de 8 a $25 \%$ (SENAI, 1999). Observa-se que todos os tratamentos apresentaram valores acima da padronização técnica, sendo que os tratamentos 2:1, 3:1 e 7:1 diferiram estatisticamente do tratamento testemunha, sendo considerados impróprios para a produção de produtos cerâmicos. Os demais tratamentos apresentaram valores maiores que o de referência, porém não diferiram estatisticamente da testemunha pelo teste de Dunnett, sendo que o tratamento 5:1 apresentou o melhor índice de absorção d'água, inclusive obtendo valor menor que o do tratamento testemunha.

Os três últimos ensaios descritos podem ser correlacionados, pois a porosidade aparente está intimamente relacionada com a massa específica aparente e absorção d'água, devido à estreita relação entre elas. Assim, quanto maior a porosidade, menor a massa específica aparente e maior a absorção d'água. Outras características também são influenciadas negativamente pela porosidade aparente, tais como a resistência mecânica e a condutibilidade térmica. 
Esses ensaios são bons indicadores da qualidade final do produto cerâmico acabado, pois medem o grau de vitrificação obtido na temperatura em que o produto foi queimado, visto que, para a mesma massa, à medida que aumenta a temperatura de queima, diminui significativamente a porosidade. Quanto maior a vitrificação da peça, menor a porosidade e, consequentemente, a absorção d'água.

\section{Tensão de ruptura à flexão a $110{ }^{\circ} \mathrm{C}$}

$\mathrm{O}$ valor mínimo de tensão de ruptura à flexão para tijolo maciço é de $15 \mathrm{kgf} / \mathrm{cm}^{2}$ para corpos de prova secos a $110{ }^{\circ} \mathrm{C}$ (SENAI, 1999). Pode-se observar, na tabela 3, que todos os tratamentos que passaram pelo processo de secagem a $110^{\circ}$ e tiveram seus corpos de prova submetidos ao teste de tensão de ruptura à flexão de secagem apresentaram resultados variando de $12,0 \mathrm{kgf} / \mathrm{cm}^{2}$ a $10,3 \mathrm{kgf} / \mathrm{cm}^{2}$, com um valor médio de $11,2 \mathrm{kgf} / \mathrm{cm}^{2}$, portanto menores que o valor mínimo padrão, inclusive para o tratamento confeccionado somente com argila.

Essa resistência à flexão da argila no estado seco está ligada à composição granulométrica do material mineral, sendo de importância secundária a sua análise, pois atua somente no processo de produção em que se procede ao manuseio do material cerâmico antes da queima. Na comparação de médias, os tratamentos 5:1, 7:1 e 9:1 diferiram do tratamento testemunha, apresentando valores menores do que ele. No entanto, considerando que na prática o tijolo só pode ser utilizado após a queima à temperatura de $950{ }^{\circ} \mathrm{C}$, todos os tratamentos foram aprovados.

\section{Tensão de ruptura à flexão a $950{ }^{\circ} \mathrm{C}$}

A tensão de ruptura à flexão a $950^{\circ} \mathrm{C}$ (TRF950) é relacionada à resistência provocada pela fusão dos componentes da argila quando submetida a altas temperaturas. $\mathrm{O}$ valor padrão para essa característica para a produção de tijolo maciço cerâmico é de $20 \mathrm{kgf} / \mathrm{cm}^{2}$ (SENAI, 1999). Observa-se, na tabela 3, que os tratamentos apresentaram um valor médio de $67,2 \mathrm{kgf} / \mathrm{cm}^{2}$ e uma variação de $54,8 \mathrm{kgf} / \mathrm{cm}^{2}$ a $87,5 \mathrm{kgf} / \mathrm{cm}^{2}$. Altas temperaturas podem ter influenciado em algumas características químicas da argila, bem como a geração de constituintes orgânicos da serragem, melhorando essa propriedade.

Todos os tratamentos apresentaram valores maiores que o valor de referência mínimo exigido. Verificou-se que a incorporação não afetou a resistência à flexão dos corpos de prova, pois todos os tratamentos não diferiram estatisticamente em relação à testemunha.

\section{Análise da argila por difração de raios $X$}

A figura 4 mostra os resultados da difração por raios $\mathrm{X}$, a qual ilustra os picos difratométricos dos minerais que compõem a argila em estudo, bem como sua modificação estrutural quando ela é submetida ao processo de queima a $950{ }^{\circ} \mathrm{C}$.

Observa-se na figura $4 \mathrm{o}$ resultado da análise mineralógica da argila por difração de raios $\mathrm{X}$ em três amostras: argila pura (em estado natural), argila pura + processo de queima a $950{ }^{\circ} \mathrm{C}$ e argila + serragem de Eucalyptus na proporção 5:1 + processo de queima a $950{ }^{\circ} \mathrm{C}$. Na amostra ao natural, pode-se visualizar intactas as estruturas do mineral, no qual o pico de difração $7,26 \AA ̊$ é característico do material caulinita (Kt), sendo do grupo $7 \AA$ (caulinitas) e com presença de quartzo (Qz) - também chamado de sílica livre - na sua constituição. O mineral Qz aparece principalmente em argilas residuais. Na sua forma macroscópica, a presença do quartzo causa redução da plasticidade e leva a argila a apresentar uma baixa retração linear quando submetida a altas temperaturas.

Nas outras duas amostras em que se procedeu à queima do material a $950{ }^{\circ} \mathrm{C}$, pode-se observar $\mathrm{o}$ desaparecimento das estruturas da caulinita $(\mathrm{Kt})$, já que a essa temperatura todas as reações físicas e químicas decorrentes da fusão de elementos constituintes da argila já se processaram, restando somente o quartzo (Qz). Esse fato acontece devido a esse mineral possuir uma temperatura de fusão acima de $1.000^{\circ} \mathrm{C}$, a qual não foi atingida no processo de queima da argila em estudo.

Observou-se também que nenhuma modificação significativa foi detectada no teste de difração na argila com incorporação de serragem na composição mineralógica após o processo de queima. Esse resultado é interessante, pois essa característica é desejável para a utilização desse processo na confecção de produtos cerâmicos.

\section{Análise química da serragem}

Foi procedida uma análise química da serragem do Eucalyptus em estudo para fins de caracterização do material, obtendo-se os seguintes valores médios: extrativos totais $(15,36 \%)$, lignina $(30,75 \%)$, holocelulose $(69,25 \%)$ e cinzas $(0,84 \%)$. A característica química que apresentou valor médio 
superior ao normalmente relatado na literatura foi o teor de extrativos totais. A madeira de Eucalyptus possui entre 5 e $7 \%$ desses extrativos, podendo variar com a espécie. Esse fato aconteceu devido ao resíduo de madeira conter partículas de casca na sua constituição.

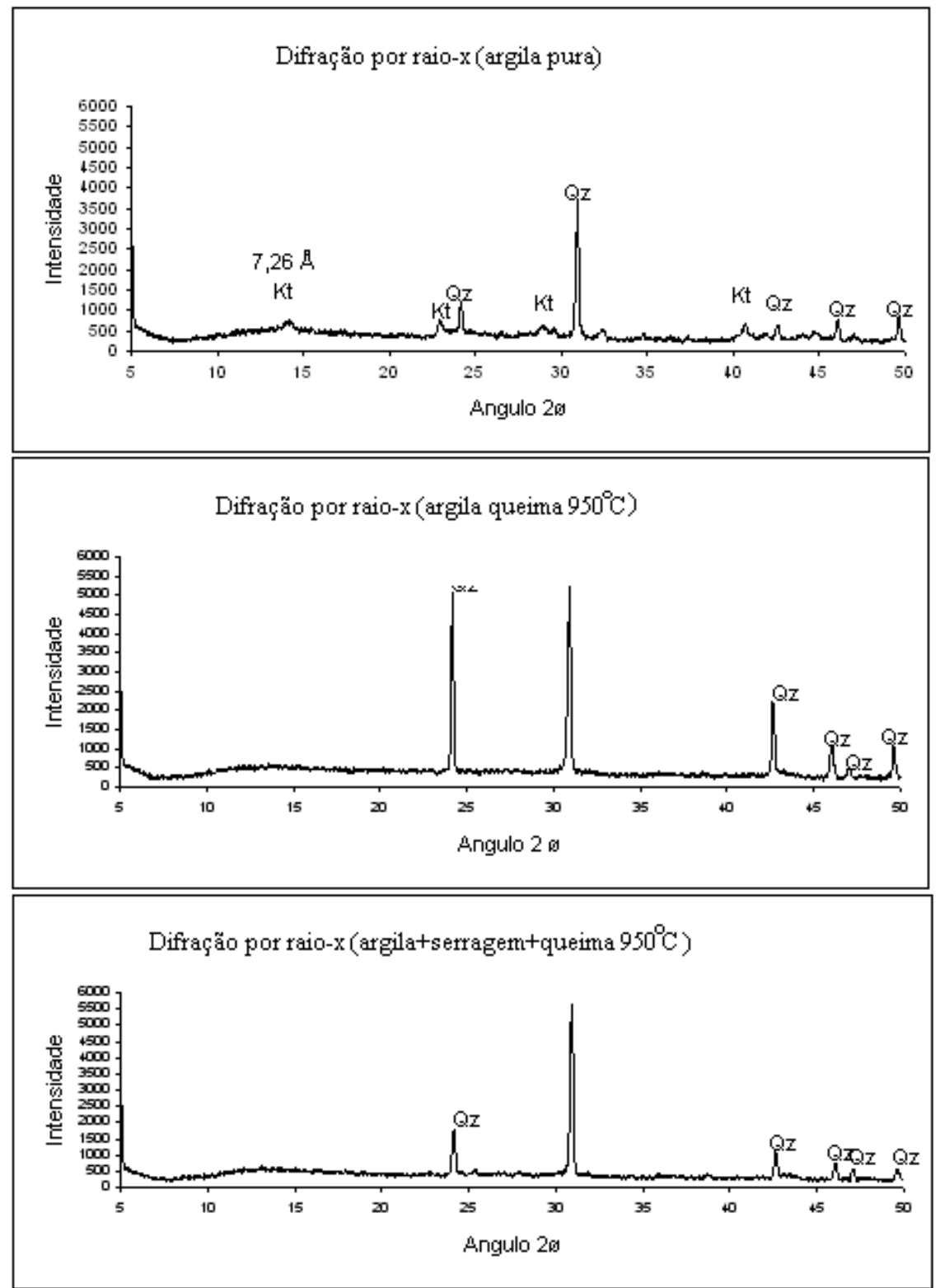

Figura 4. Teste de difração por raios $\mathrm{X}$ em três amostras de argila e seus picos difratométricos da caulinita (Kt) e do quartzo (Qz).

Figure 4. Test of diffraction for X-ray, in three clay samples and its diffractometrics peaks of the caulinita $(\mathrm{Kt})$ and the quartz $(\mathrm{Qz})$.

A serragem incorporada no processo de produção do tijolo maciço cerâmico, por se tratar de um material mais leve que a argila e ter toda sua estrutura quebrada quando submetido a altas temperaturas, deixando como resíduo aproximadamente $0,84 \%$ do seu peso na forma de cinzas, confere ao novo produto confeccionado uma diminuição do peso em relação aos tijolos convencionais. 
Na tabela 4 verifica-se a diferença média de peso dos corpos de prova de $110 \times 28$ x $18 \mathrm{~mm}$ entre os tratamentos com incorporação de serragem de Eucalyptus e o tratamento testemunha confeccionado somente com argila.

Tabela 4. Diferença média de peso entre o tratamento testemunha confeccionado com argila e os tratamentos originários da mistura de diferentes traços de argila e serragem de madeira.

Table 4. Average difference of weight enters the treatment testifies confectioned with clay and the originary treatments of the mixture of different clay traces and wooden sawdust.

\begin{tabular}{lccc}
\hline Tratamentos & P. médio $(\mathbf{g})$ & Diferença de peso $(\mathbf{g})$ & Diferença de peso $(\%)$ \\
\hline $\mathrm{T}$ & 55,24 & - & - \\
$2: 1$ & 43,38 & 11,86 & 21,5 \\
$3: 1$ & 44,51 & 10,73 & 19,4 \\
$4: 1$ & 47,19 & 8,05 & 14,6 \\
$5: 1$ & 48,22 & 7,02 & 12,7 \\
$6: 1$ & 49,05 & 6,19 & 11,2 \\
\hline
\end{tabular}

Conforme Pereira et al. (1997), a densidade média do resíduo da madeira de Eucalyptus varia numa faixa de 0,4 a $0,7 \mathrm{~g} / \mathrm{cm}^{3}$.

No presente estudo, observa-se que a densidade básica da argila estudada foi de $1,6 \mathrm{~g} / \mathrm{cm}^{3}$. Desse modo, a adição gradativa de um material de menor densidade que a argila na confecção de tijolo maciço cerâmico irá favorecer a diminuição do peso final do mesmo.

Essa é uma das características desejáveis para muitas empresas do ramo da construção civil, pois um produto cerâmico com peso inferior aos tradicionalmente utilizados irá favorecer a diminuição das dimensões das estruturas de sustentação de seus empreendimentos, o que acarretará em uma diminuição dos custos.

Para a escolha da mistura argila/serragem que iria compor a produção do tijolo maciço cerâmico na indústria, levou-se em consideração o maior percentual de incorporação de serragem possível, sendo que este não podia interferir na qualidade final do produto cerâmico acabado.

\section{CONCLUSÕES}

- Verificou-se que existe a viabilidade técnica em diferentes misturas de argila/serragem de Eucalyptus para produção de produtos cerâmicos, tendo em vista que boa parte das características físicomecânicas foi próxima aos valores de referência. Em relação à resistência mecânica dos tijolos produzidos, uma boa incorporação foi de oito partes de argila e uma de serragem. Nas demais propriedades, uma incorporação de no mínimo seis partes de argila e uma parte de serragem.

- Na caracterização mineralógica por difração de raios X, a argila em estudo se enquadrou no grupo das cauliníticas, e não foi detectada qualquer variação na sua constituição no tratamento com incorporação de serragem nas diferentes proporções estudadas.

- A análise química da serragem de Eucalyptus spp. apresentou resultados em conformidade com os descritos na literatura, exceto a característica extrativos totais, que apresentou um valor superior.

\section{REFERÊNCIAS}

ASSOCIAÇÃO BRASILEIRA DE CELUlOSE E PAPEL (ABCP). Prep. de madeira livre de extrativos, ABCP M3/69. São Paulo, 1969. 3 p.

Determinação de cinza na madeira, ABCP M11/71. São Paulo, 1971a. 1 p.

Lignina na madeira, ABCP M10/71. São Paulo, 1971b. 2 p.

Solubilidade da madeira em água, ABCP M4/68. São Paulo, 1968. 1 p.

Umidade de madeira reduzida à serragem por secagem em estufa, ABCP M2/71. São Paulo, 1971. 1 p. 
ASSOCIAÇÃO BRASILEIRA DE NORMAS TÉCNICAS (ABNT). Tijolo maciço cerâmico para alvenaria, NBR 7170. Rio de janeiro, 1983. 6 p.

BANZATTO, D. A.; KRONKA, S. N. Experimentação agrícola. 3. ed. Jaboticabal: FUNEP, 1985. 247 p.

COCCHI, M. C. Ensaios cerâmicos: normas de laboratório. São Paulo: CENATEC/SENAI, 1990. 24 p.

COVEZZI, M. M. Incorporação de serragem de Erisma uncinatum WARM. ("cedrinho"), oriunda da indústria madeireira, na produção de tijolo maciço cerâmico. 64 p. Monografia (Graduação em Engenharia Florestal) - Universidade Federal do Mato Grosso, 1999.

MÜLLER, S. L. Curso de cerâmica vermelha. Santa Maria: UFSM, 1990.

PEREIRA, J. C. D.; SCHAITZA, E. G.; HIGA, A. R. Caracterização dos resíduos da madeira de Eucalyptus como fonte de energia. São Paulo: EMBRAPA, 1997. 3 p. (Boletim Técnico, 36).

SERVIÇO NACIONAL DE APRENDIZAGEM INDUSTRIAL (SENAI). Relatório de ensaios de caracterização de argilas. Cuiabá: SENAI, Laboratório de Cerâmica, 1999. 18 p.

VERÇOSA, E. J. Argilas e materiais cerâmicos. In: BAUER, L. A. F. Materiais de construção. Rio de Janeiro: LTC Editora, 1994. v. 2, p. 527 - 576. 
FLORESTA, Curitiba, PR, v. 41, n. 3, p. 641-654, jul./set. 2011

Mori, F. A.; Covezzi, M. M.; Mori, C. L. S. de O. 